\title{
Neonatal Morbidity and Mortality trend in a Special Care baby Unit of a Tertiary Hospital in Yola: the need to educate health workers and mothers on quality neonatal health practices
}

\author{
Baba Usman Ahmadu*, Hamman Isah Babba, Joda Aisha Abdallah, Abraham Musa Tizhe, \\ Akor Ogecha, Pius Sunday, Yakubu Hyeladi Francis, Gamdu Jesini
}

Department of Paediatrics, Federal Medical Centre, Yola, Adamawa State, Nigeria

\section{Email address:}

ahmadu4u2003@yahoo.com (B. U. Ahmadu),binhamman@yahoo.co.uk (H. I. Babba), diyajoda@yahoo.co.uk (J.A. Abdallah) musaabraham14@yahoo.com (A. M. Tizhe),snipcee@yahoo.com (A. Ogecha), sonyp001@yahoo.com (P. Sunday), hyelboy94@nokiamail.com (Y. H. Francis),montaz4eva@yahool.com (G. Jesini)

To cite this article:

Baba Usman Ahmadu, Hamman Isah Babba, Joda Aisha Abdallah, Abraham Musa Tizhe, Akor Ogecha, Pius Sunday, Yakubu Hyeladi Francis, Gamdu Jesini. Neonatal Morbidity and Mortality Trend in a Special Care baby Unit of a Tertiary Hospital in Yola: the Need to Educate Health Workers and Mothers on Quality Neonatal Health Practices. American Journal of Health Research.

Vol. 1, No. 3, 2013, pp. 99-103. doi: 10.11648/j.ajhr.20130103.20

\begin{abstract}
Background: Neonatal morbidities like neonatal sepsis (NNS), prematurity and perinatal asphyxia constitutes the major causes of neonatal mortality worldwide, even though, there may be slight intra and inter country variations. Objective: The main objectives of our study were twofold: 1) To determine the morbidity and mortality pattern of neonates admitted to the Special Care Baby Unit (SCBU) of the Federal Medical Centre Yola (FMCY), Adamawa state. 2) To provide relevant public health information that will be of benefit in reducing neonatal morbidity and mortality. Methods: A hospital-based retrospective study was carried out. Case notes of neonates admitted and managed for various morbidities at the SCBU of the FMCY over a period of seven months between April 2012 and October 2012 were retrieved and reviewed using a structured questionnaire, to document demographic characteristic, diagnosis and the number of deaths that occurred. Statistical analyses were performed by use of SPSS statistical software version 16, Illinois, Chicago USA and a computer program for epidemiologist PEPI version 3.01. Results: Total admission for the period was 292 (100\%). There were 124 $(42.5 \%)$ males and $168(57.5 \%)$ females. The male to female ratio is $1: 1.4$. Highest morbidity $47(72.3 \%)$ was observed in April, but highest mortality was bimodal, one in April 14 (27.7 \%) and the other 14 (26.9 \%) in August. Overall association of the morbidity and mortality figures for the period was not significant $(p=0.296)$. The mean Morbidity and mortality was $33.0(8.9)$ and 8.7 (4.5) respectively. Multivariate test showed a significant difference between NNS on the combined dependent variables (morbidity and mortality), $\mathrm{p}=0.012$. When the results for the dependent variables were considered separately in a Univariate model using a Bonferroni adjusted alpha levels, both dependent variables were significance at $p=0.001$ for morbidity and $p=0.000$ for mortality. Conclusions: Neonatal sepsis and prematurity were the major causes of neonatal mortality, whereas, severe perinatal asphyxia was the second cause of morbidity in this study.
\end{abstract}

Keywords: Neonatal Morbidity and Mortality, Special Care Baby Unit, Care-Giver and Health Worker Education, Adamawa State, Nigeria

\section{Introduction}

Millions of neonates die annually and most of these deaths are occurring in Sub-Saharan regions of the world and Asia [1]. Lack of resources such as money, qualified manpower and hospital equipments could be the reason for the high morbidity and mortality rates in these developing regions of the world [2]. Nigeria is faced with problems of neonatal morbidity (NM) and the country has a neonatal mortality rate (NMR) of 53 per 1000 live births [3]. This figure is higher than the average for the African continent, which was put at 43 per 1000 live births [3]. A paper by Manzar et al, [4] in Karachi, Pakistan, in 2012 puts the countries NMR at 56 per 1000 live births. Most of the 
neonatal deaths in developing countries of the world especially, are caused by neonatal sepsis (NNS), prematurity, severe perinatal asphyxia and congenital anomaly among other causes. In fact, three-quarter of NMR are caused by neonatal sepsis, prematurity and severe birth asphyxia according to Lawn et al, [5] in 2005.

Developing countries have certain peculiar characteristics, which include high fertility rates, high poverty rates; low literacy rates especially that of women, low patronage for family planning and so forth [3, 4]. All these are contributors to high NM and mortality. The importance of reducing NM and NMR cannot be overemphasized because one of the United Nation's Millennium Development Goal is to reduce the under five childhood mortality rate by two-third by the year 2015 [6]. Since neonatal mortality constitutes 41 percent of all deaths in children under the age of five years, reducing the NMR would also help to reduce the under five mortality, thereby, ensuring quality of life to children [6].

The burden of NM and mortality vary from place to place, and dearth of knowledge still exists on this issue particularly in our setting. Therefore, the main objectives of our study were twofold: 1) To determine the morbidity and mortality pattern of neonates admitted to the Special Care Baby Unit (SCBU) of the Federal Medical Centre Yola (FMCY), Adamawa state. 2) To provide relevant public health information that will assist in reducing $\mathrm{NM}$ and mortality in our environment and beyond. To the best of our knowledge there is no study or data on this subject matter especially in Yola, Adamawa state, North-Eastern Nigeria after extensive literature search.

\section{Materials \& Methods}

\subsection{Study Area}

The study was carried out at the SCBU of the Department of Paediatrics, FMCY, Adamawa state, Nigeria. The FMCY is a tertiary health care centre located in NorthEastern Nigeria. It also serves as a referral site for the other health institutions especially from the twenty one Local Government Areas of the state and the neighboring communities. The study area is defined by longitude $13.5^{\circ}$ $\mathrm{E}$ and latitude $11^{0} \mathrm{~N}$. The characteristic vegetation is that of Sub-Sudan and Guinea savannah with an average annual rainfall of $79 \mathrm{~mm}$ and $197 \mathrm{~mm}$ in the northern and southern part of the state and temperature range of $15{ }^{\circ} \mathrm{C}-39.7{ }^{\circ} \mathrm{C}$. There are two distinct seasons: the wet and the dry seasons; the former takes place between April and October, while the latter occurs from November to March. The state is multi-ethnic with a population of about 3.2 million; Christianity and Islam are the major religions.

\subsection{Design}

The study was a hospital-based retrospective study. Case notes of neonates admitted and managed for various morbidities at the SCBU of the FMCY over a period of seven months between April 2012 and October 2012 were retrieved and reviewed using a structured questionnaire, to document demographic characteristic, diagnosis reached and the number of deaths that occurred in the course of managing the different morbidities.

\subsection{Ethical Issues}

This study was carried out in compliance with guidelines of the Helsinki declaration on biomedical research on human subjects. The study protocol was reviewed and authorized by the Medical Research and Ethics Committee of the FMCY.

\subsection{Data Analysis}

Data analyses were performed using SPSS statistical software version 16, Illinois, Chicago USA and a computer program for epidemiologist PEPI version 3.01. Descriptive data were presented in tables. Preliminary checks were conducted to ensure that there was no violation of the assumptions of normality, linearity and homogeneity of variance. Multivariate analysis was used to investigate the effects of NNS as a diagnosis (fixed factor) on the combined morbidity and mortality (dependent factors). Benferroni adjusted Univariate analysis was used to investigate the dependent variables separately. Student $t$ test and Chi-square were also used to compare quantitative and categorical variables. A p value $<0.05$ was considered significant.

\section{Results}

Total SCBU admission for the period was 292 (100\%). There were $124(42.5 \%)$ males and $168(57.5 \%)$ females. The male to female ratio is $1: 1.4$. Table 1 shows monthly admission during the seven month period. Highest morbidity 47 (72.3 \%) was observed in April, but highest mortality had dual peaks, one in April 14 (27.7\%) and the other $14(26.9 \%)$ in August. Overall association of the morbidity and mortality figures for the period reviewed was not significant $(\mathrm{p}=0.296)$. The mean morbidity and mortality was 33.0 (8.9) and 8.7 (4.5) respectively (Table 2).

Table 1: Morbidity and mortality profile of the neonates from April to October

\begin{tabular}{ccccc}
\hline Months & $\begin{array}{c}\text { Morbidities } \\
\mathbf{n}(\%)\end{array}$ & $\begin{array}{c}\text { Mortalities } \\
\mathbf{n}(\%)\end{array}$ & p value $^{\mathbf{a}}$ & Total \\
\hline April & $47(72.3)$ & $14(27.7)$ & - & 61 \\
May & $21(84.0)$ & $4(16.0)$ & 0.669 & 25 \\
June & $27(84.4)$ & $5(15.6)$ & 1.000 & 32 \\
July & $27(69.2)$ & $12(30.8)$ & 0.227 & 39 \\
August & $38(73.1)$ & $14(26.9)$ & 0.688 & 52 \\
September & $39(88.6)$ & $5(11.4)$ & 0.099 & 44 \\
October & $32(82.1)$ & $7(17.9)$ & 0.590 & 39 \\
Total & 231 & 61 & - & 292 \\
\hline
\end{tabular}

$\mathrm{p}$ value ${ }^{\mathrm{a}}=$ Chi-square $(\chi 2)$ trend. 
Table 2: Mean morbidity and mortality of the study group

\begin{tabular}{ccc}
\hline Variables & Mean (SD) & $\mathbf{9 5 \% ~ C I ~}$ \\
\hline Morbidity & $33.0(8.9)$ & $24.78-41.22$ \\
& & \\
Mortality & $8.7(4.5)$ & $4.6-12.8$ \\
$\mathrm{p}=$ value $^{\mathrm{b}}$ & $0.000^{*}$ & - \\
\hline
\end{tabular}

$*=\mathrm{p}$ value $<0.05$ significant, $\mathrm{SD}=$ Standard deviation, $\mathrm{CI}=$ Confidence interval,

$p$ value ${ }^{b}=$ Student $t$ test.

Table 3 shows breakdown of morbidities and mortalities of the subjects based on the diagnosis that was made at admission. Neonatal sepsis had the highest morbidity and mortality values in this work. Multivariate test showed a significant difference between NNS on the combined dependent variables (morbidity and mortality), $\mathrm{p}=0.012$
(Table 4). When the results for the dependent variables were considered separately in a Univariate model using a Bonferroni adjusted alpha levels, both dependent variables were significance at $\mathrm{p}=0.001$ for morbidity and $\mathrm{p}=0.000$ for mortality (Table 5).

Table 3: Summary of morbidities and mortalities with their diagnosis

\begin{tabular}{llll}
\hline Diagnosis * & $\begin{array}{l}\text { Morbidities } \\
\mathbf{n}(\%)\end{array}$ & $\begin{array}{l}\text { Mortalities } \\
\mathbf{n}(\%)\end{array}$ & Total \\
\hline Neonatal sepsis & $202(87.4)$ & $57(93.4)$ & 259 \\
Congenital anomaly & $7(3.0)$ & $1(1.6)$ & 8 \\
Severe perinatal asphyxia & $14(6.1)$ & $1(1.6)$ & 15 \\
Prematurity & $8(3.5)$ & $2(3.3)$ & 10 \\
Total & 231 & 61 & 292 \\
\hline
\end{tabular}

*Some neonates had more than one diagnosis

Table 4: Multivariate tests of effect of neonatal sepsis on neonatal morbidity and mortality

\begin{tabular}{cccccccc}
\hline Effect & & Value & F & Hypothesis df & Error df & p value $^{\mathbf{c}}$ & Partial Eta Squared $^{2}$ \\
\hline \multirow{2}{*}{ NNS } & Pillai's Trace & 1.000 & $3.425 \mathrm{a}$ & 2.000 & 1.000 & $0.012 *$ \\
& Wilks' Lambda & 0.000 & $3.425 \mathrm{a}$ & 2.000 & 1.000 & $0.012 *$ \\
& Hotelling's Trace & 6.850 & $3.425 \mathrm{a}$ & 2.000 & 1.000 & $0.012 *$ \\
& Roy's Largest Root & 6.850 & $3.425 \mathrm{a}$ & 2.000 & 1.000 & $0.012 *$ \\
\hline
\end{tabular}

$*=\mathrm{p}$ value $<0.05$ significant, $\mathrm{a}=$ Exact statistic, $\mathrm{NNS}=$ Neonatal sepsis, $\mathrm{p}$ value ${ }^{\mathrm{c}}=$ Multivariate analysis.

Table 5: Univariate tests of effect of neonatal sepsis on neonatal morbidity and mortality

\begin{tabular}{cccccccc}
\hline Source & $\begin{array}{c}\text { Dependant } \\
\text { variables }\end{array}$ & $\begin{array}{c}\text { Type III sum } \\
\text { squares }\end{array}$ & Df & Mean square & F & $\begin{array}{c}\text { Partial Eta } \\
\text { Squared }\end{array}$ \\
\hline \multirow{2}{*}{ NNS } & Morbidity & $27744.083^{\mathrm{a}}$ & 1 & 27744.083 & 1.936 & $0.001^{*}$ \\
& Mortality & $2324.083^{\mathrm{b}}$ & 1 & 2324.083 & 6.972 & $0.000^{*}$ \\
\hline
\end{tabular}

a. R Squared $=0.999$ (Adjusted R Squared $=0.998)$, b. R Squared $=1.000$ (Adjusted R Squared $=1.000), *=p$ value $<0.05$ significant, NNS $=$ Neonatal sepsis, $\quad$ v value $^{\mathrm{d}}=$ Uniivariate analysis.

\section{Discussions}

Neonatal sepsis in this work was the major cause of neonatal ill-health and deaths. Similar finding was reported by Owa and Osinaike [7], in 1998 in Nigeria, Ayaz and Saleem [8], in Pakistan in 2010 and Kouéta et al [9], in France in 2004. The consistency with which NNS was ranked as the topmost cause of neonatal sickness and demise from the studies above engulfed both developed and developing countries. Therefore, geographical, spatial and demographic differences did not differ much on the fact that NNS as a diagnosis was responsible for high newborn morbidity and mortality. More evidence to further support this fact may be seen from a study conducted by Oestergaard et al [6], in 2011, with world-wide participation. The major geographical and regional differences could possibly be epidemiologic because microorganisms isolated in developed countries differ greatly from those seen in developing countries. While
Staphylococcus aureus and Klebsiella were the most common isolate in developing communities, Gram negative infections were more common than gram positive organisms in advanced societies [4]. Worthy of emphasis is that isolated microbial causes of NNS was not part of our study objectives and therefore was not included in our data.

Severe perinatal asphyxia contributed the second most common cause of neonatal morbidity and prematurity rated the second most common cause of neonatal death in current study. This agrees to findings by Modi and Kirubakaranand [10], in 1995 in India, where prematurity was ranked next to NNS regarding deaths of newborns. This finding was, however, not consistent because other investigators have published prematurity as the most common cause of neonatal mortality followed by NNS [4]. Yet, in another study, severe perinatal asphyxia was next to prematurity as a cause of morbidity and mortality in neonates [11]. Omoigberale et al [12], in Benin city, Nigeria, in 2010, highlighted on NNS, severe perinatal asphyxia and 
prematurity to be the most important three morbidities in that order with grave consequences. After NNS, prematurity and perinatal asphyxia, another important morbidity that is also associated with neonatal death is congenital anomaly and this was evidenced in present study. Similar observation was made by other colleagues working independently and also at the annual Paediatric conference of Nigeria [13, 14].

Whereas, morbidity was observed to peak in April in this study, mortality had bimodal peaks one in April and the other in August. It is deducible to attribute rising number of deaths to increased number of SCBU admissions (morbidities). However, it is not fully clear why those months had peaks for both morbidity and mortality. Going by our SCBU record, highest number of admissions occurred in April and August. This could be the likely explanation for the trend that was observed in this study even though the values were not significant statistically.

The newborn period is a vulnerable time period because certain physiological adjustments are needed for survival outside the mother's womb. Therefore, this period would require skilled personnel to attend to mothers before delivery and their neonates after delivery. This is necessary in order to reduce the risk of the babies being infected, and also to decrease the morbidity and mortality that could arise from prematurity, severe perinatal asphyxia and congenital anomaly among other causes. To further add, the World Health Organization (WHO) stated that complications arising from pregnancy or delivery, NNS and malformed neonates are major causes of NM and mortality [15]. The neonates, having their extra-uterine physiologic changes compromised by aforesaid morbidities, high number of mortalities are likely to result as seen in the present study. This again explains the statement by WHO and Lawn et al, that a high proportion of newborns die within the first month of life $[3,5,15]$.

Going by the evidence seen in this study, neonates especially in resource poor settings are prone to sickness and death from causes that can be modified or prevented by maternal and child health intervention. Skilled and institutional deliveries have the lowest figures in terms of NM and mortality as presented in a paper by Bhutta et.al [16], in 2003. Neonatal resuscitation, therefore, is key to newborn survival and prompt resuscitation after delivery can prevent many NM and mortalities. In addition to adequate nutrition, immunization and skilled delivery for pregnant mothers, early breast feeding of the neonate and in case of NM, prompt intervention may on the overall prevent or reduce neonatal mortality.

\section{Conclusions}

Neonatal sepsis and prematurity were the major causes of neonatal mortality, whereas, severe perinatal asphyxia was the second cause of morbidity in current work.

\section{Limitations}

This work was conducted in a single hospital (FMCY); therefore, there is the need to be cautious in generalizing the data of this study. More so, the study did not look at socio-economic class of care givers as an indicator of financial resource. This also is a setback because financial constrain on the part of care-givers would amount to irregularity and non-affordability of drugs and other consumables that are needed for quality neonatal care. As such there will be very high figures of newborn morbidity and mortality.

\section{Recommendations}

Based on the findings of this work, it is recommended that pregnant women should be educated and encouraged to visit health care institutions during pregnancy and childbirth. It is also recommended that newborn units should have a workable program for managing cases, most especially NNS; again health workers and traditional birth attendants (TBA) should be trained on newborn care, such as, neonatal resuscitation.

\section{Competing Interests}

All authors also declare that they have no conflict of interest.

\section{Funding Source}

The authors funded this work.

\section{Contributors}

BUA conceived, designed and interpreted the data of the study; BUA, HIB, JAA, AMT and AO assessed the paper. BUA, PS, YHF and GJ wrote the draft report; however, all authors were also involved in the critical revision of the paper.

\section{Acknowledgements}

We sincerely wish to thank the Medical Record Staff of the FMCY for their assistance in retrieving the Patients case notes and providing the statistics of total SCBU admission for the period reviewed.

\section{References}

[1] Zupan J. Perinatal mortality in developing countries. N Engl J Med 2005;352:2047-48.

[2] Ngoc NT, Merialdi M, Abdel-Aleem H, Carroli G, Purwar M, Zavaleta $\mathrm{N}$, et al. Causes of stillbirths and early neonatal deaths: Data from 7933 pregnancies in six developing countries. Bull World Health Organ 2006;84:699-705. 
[3] World Health Organization. Country health system fact sheet Nigeria 2006. Lagos.

[4] Manzar N, Manzar B, Yaqoob A, Ahmed M, Kumar J. The study of etiological and demographic characteristics of neonatal mortality and morbidity - a consecutive case series study from Pakistan. BMC Pediatrics 2012;12:131-7.

[5] Lawn JE, Cousens S, Zupan J. 4 million neonatal deaths: when? Where? Why? Lancet 2005; 365:891-900.

[6] Oestergaard MZ, Inoue M, Yoshida S, Mahanani WR, Gore FM, et al. Neonatal Mortality Levels for 193 Countries in 2009 with Trends since 1990: A Systematic Analysis of Progress, Projections, and Priorities. PLoS Med 2011; 8(8):e1001080.

[7] Owa JA, Osinaike AI: Neonatal morbidity and mortality in Nigeria. Indian J Pediatr 1998; 65(3):441-49.

[8] Ayaz A, Saleem S: Neonatal Mortality and Prevalence of Practices for Newborn Care in a Squatter Settlement of Karachi, Pakistan. A Cross- Sectional Study. PLoS One 2010; 5(11):e13783.

[9] Kouéta F, Yé D, Dao L, Néboua D, Sawadogo A. Neonatal morbidity and mortality in 2002-2006 at the Charles de gulle pediatric hospital (France). Child Care Health Dev 2004, 30(6):699-709.
[10] Modi N, Kirubakaran C: Reasons for admission,causes of death and costs of admission to a tertiary neonatal referral unit in India. J Trop Pediatr 1995;4(2):99-102.

[11] Seyal T, Husnain F, Anwar A. Audit of Neonatal Morbidity and Mortality at Neonatal Unit of Sir Gangaram Hospital Lahore. Ann King Edward Med Uni 2011;17(1):9-13.

[12] Omoigberale AI, Sadoh WE, Nwaneri DU. A 4 year review of neonatal outcome at the University of Benin Teaching Hospital, Benin city. Nig J Clin Pract 2010;13(3):321-25.

[13] Onasoga OA, Oluwatosin AO, Ojo AA. Predictors of Neonatal Morbidity and Mortality in Tertiary Hospital in Ogun State, Nigeria. Arch Appl Sci Res 2012;4(3):1511-16.

[14] Okolo A. Overview of Neonatal Mortality - Global Perspectives. PANCONF 2009;S1-S43.

[15] World Health OrganizationNeonatal and Perinatal Mortality Country, Regional and Global Estimates;WHO Library Cataloguing-in-Publication Data 2006.

[16] Bhutta ZA, Darmstadt GL, Hasan BS, Haws RA. Pediatrics 2005;115;519-617. 